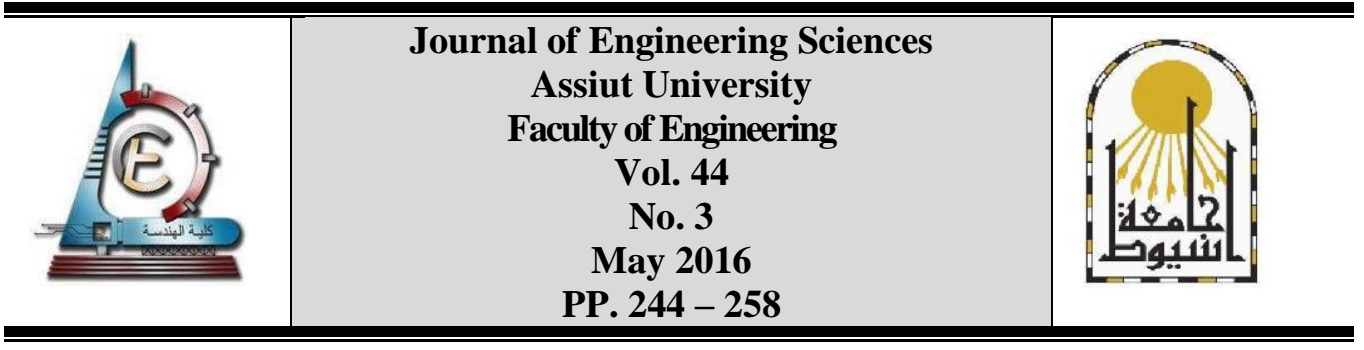

\title{
INFLUENCE OF MIXTURE COMPOSITION ON WASHOUT RESISTANCE, FRESH PROPERTIES AND RELATIVE STRENGTH OF SELF COMPACTING UNDERWATER CONCRETE
}

\author{
Abd Elrahman Megahed ${ }^{1}$, Ihab Adam ${ }^{2}$, Omar Farghal ${ }^{3}$, Mohamed Omar Sayed 4, * \\ ${ }^{1,3}$ Civil Eng. Dept., Assuit University \\ ${ }^{2,4}$ Construction Research Institute, National Water Research Center, Egypt
}

Received 13 March 2016; Accepted 14 May 2016

\begin{abstract}
Successful design of underwater concrete mixtures must fulfill two basic requirements: adequate flow ability to spread into the placing forms without consolidation, and viscosity in order to resist the washing out. In this paper an investigation was carried out to determine the effect of the dosage of anti washout admixture (AWA), water cementitious materials ratio $(\mathrm{w} / \mathrm{cm})$,sand to total aggregate ratio $(\mathrm{s} / \mathrm{a})$, and the supplementary cementitious materials on the washout resistance, fresh properties and the relative compressive strength of self-compacting underwater concrete (SCUWC). Therefore five groups were prepared for this study. First group studied the effect of the supplementary cementitious materials, second group dealt with the effect of the AWA ratios, third group is concerning with the effect of $\mathrm{w} / \mathrm{cm}$ ratio, fourth group take into account the effect of s/a ratio and finally fifth group included the effect of cementitious materials. Test results indicate that the concentrations of antiwashout admixture (AWA) have direct effect on washout resistance and relative compressive strength. The washout mass loss can be reduced by using $10 \%$ silica fume replacement. Also it can be reduced by decreasing the $\mathrm{w} / \mathrm{cm}$ and increasing the cement content and that result in greater relative strength.
\end{abstract}

Keywords: Underwater concrete; Self compacting concrete; Antiwashout admixture (AWA); Washout resistance; Silica fume

\section{Introduction}

Until recently, underwater concrete was defined as tremie concrete only, but now, due to recent researches in the field of using admixtures, new procedures have been developed, so freshly mixed concrete can now be placed by dropping it through water without the use of a tremie [1]. Research has improved techniques for placing concrete under water without the use of a pump, tremie, or any conventional methods, and innovative antiwashout chemical admixtures (AWA) have been developed that permit freshly mixed concrete to be placed through water without segregation or separation.

\footnotetext{
* Corresponding author.

Email address: eng_momar2010@yahhoo.com
} 
The underwater concrete should be designed to achieve good balance between the rheological and mechanical properties that have a direct effect on its performance. The resistance of concrete to water dilution and segregation is dictated by its composition and rheological properties. Among effective measures to minimize washout and segregation is incorporation of an antiwashout admixture (AWA). With combined addition of AWA and a high-range water reducing agent (HRWR), flowable, yet viscous, concrete can be obtained to secure high stability of the fresh mixture [2]. For example, the Japan Society of Civil Engineers (JSCE) recommends limiting the w/cm to 0.50 and 0.55 when casting reinforced concrete in seawater and fresh water, respectively. These values can be 0.60 and 0.65 , respectively, for nonreinforced concrete [3] [4]. Furthermore, it was recognized that the substitution of cement mass by $8 \%$ silica fume or $20 \%$ fly ash can enhance the resistance to washout, segregation, and surface settlement compared with concrete made without any supplementary cementitious materials [5].

The concrete for underwater placement requires optimum proportion of various combinations of parameters including supplementary cementitious material, water cementitious materials ratio, sand to total aggregates ratio and chemical admixtures.

The objective of this study is to investigate the effect of the AWA, w/cm, s/a, cement content, supplementary cementitious materials on the washout resistance, fresh properties and relative strength of self-compacting underwater concrete.

\section{Used materials}

All materials used throughout this research program were selected carefully from among the commercially available materials in Egypt, taking into consideration the general rules for selecting constituent materials for underwater concrete production.

\subsection{Cement}

Ordinary Portland cement (CEM I 42.5 N), was used in all concrete mixtures involved in this study. It is produced according to the Egyptian standards E.S 4756-1/2009 [6].

\subsection{Silica fume}

Silica Fume, with specific gravity of 2.2 and surface area of $22,880 \mathrm{~m}^{2} / \mathrm{kg}$, was the only supplementary cementitious material added to self-compacting underwater concrete (SCUWC) mixtures. Silica fume was added in the form of a dry powder as a percentage of the total cementitious materials (cement + silica fume) content. The density is about (1.5$2.0) \mathrm{g} / \mathrm{cm}^{3}$ and the $\mathrm{pH}$ value is from $(6-8)$.

\subsection{Fine aggregate}

Local available natural siliceous sand was used in this study with specific gravity 2.61 .

\subsection{Coarse aggregate}

The coarse aggregate used in this study was natural siliceous gravel with a nominal maximum size of $20.00 \mathrm{~mm}$ and specific gravity 2.60 . 


\subsection{Anti washout admixture (AWA)}

Sika UCS Pak is a powdered underwater/antiwashout admixture used to produce underwater concrete. It is formulated to increase the cohesion of concrete to enable significant reductions in washout. The density is about $0.50 \mathrm{~kg} / \mathrm{lit}$ and the total Chloride Ion content is less than $0.1 \%$ [7].

\subsection{Visco crete (VA)}

Sika ViscoCrete-5930L (High Performance Superplasticizer Concrete Admixture) was used in producing tested mixtures for SCUWC.it is aqueous solution of modified Polycarboxylate of density $1.1 \mathrm{~kg} / \mathrm{lit}$. It facilitates extreme water reduction, excellent flowability at the same time optimal cohesion and highest self-compacting behavior [7].

\section{Mix proportioning}

Self-compacting underwater concrete (SCUWC) mix proportioning is a more critical process than the design of self-compacting concrete (SCC). The mix proportion of (SCUWC) shall be determined by tests such that the concrete has the required antiwashout properties, strength, flowability, and durability. The procedure for self-compacting underwater concrete is firstly to select the quantity of antiwashout admixture and high-range water-reducing agent according to the required antiwashout properties and flowability. The experimental program consists of five groups. Group one is devoted to study the effect of use of supplementary cementitious materials by $10 \%$ silica fume. Four different AWA ratio values of $0.10 \%, 0.15 \%$, $0.21 \%$ and $0.23 \%$ (ratio of cementitious materials) were adopted in group two to study and determine the optimum ratio of AWA and its effect on washout resistance, fresh properties and relative strength. Group three is devoted to investigate the effect of w/cm ratio. The water cementitious materials ratios were set at $0.45,0.40$ and 0.37 corresponding to high quality of self-compacting underwater concrete. Group four is devoted to investigate the effect of s/a ratio. Three different s/ratios of $0.40,0.50$, and 0.60 , were used for mixtures. Two different cementitious materials content (CM) of 460 , and $520 \mathrm{~kg} / \mathrm{m}^{3}$, were used to investigate the effect of cementitious materials content (CM). More details of mix proportions are given in Table 1 .

The slump flow of all mixtures of (SCUWC) were intended to be kept constant; $(570 \pm 20)$ that can considered as self-compacting concrete (SCC) mixtures for underwater application as Khayat and Assaad mentioned [4] therefore, many trials were carried out to adjust the (VA content. The Self-Compacting Concrete mixtures, admixture type and combined type (SCC-A and SCC-C) were made to be control mixture. Therefore their

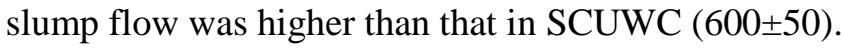

\section{Mixing procedure}

All mixtures were prepared in the laboratory using a rotating drum mixer 100 liter capacity. Buttering of the mixer (disposal of the first mix) was always carried out before the first intended mix was prepared on the day of casting. The following mixing procedure was used for all SCC mixtures involved in this study. First, the total content of cement, sand, and coarse aggregate were dry mixed all together in the mixer for 1 minute. Second, water was added and the mixing was continued for a further 2 minutes. VA was then added and the mixing process was continued for further 2 minutes. Once the mix was determined to have sufficient visual attributes of SCC, the rheological tests were performed in quick succession. 
The following mixing procedure was used for all SCUWC mixtures in this study. First, the total content of cement, sand, coarse aggregate and AWA were dry mixed all together in the mixer for 1 minute. Second, water was added and the mixing was continued for a further 2 minutes. VA or superplasticizer was then added and the mixing process was continued for further 4 minutes. Once the mix was determined to have sufficient visual attributes of SCUWC, the rheological tests were performed in quick succession.

Table 1.

Concrete mix proportions

\begin{tabular}{|c|c|c|c|c|c|c|c|}
\hline \multirow{2}{*}{ Mix } & \multirow{2}{*}{ w/cm } & \multicolumn{6}{|c|}{ Weight per unit volume $\left(\mathrm{kg} / \mathrm{m}^{3}\right)$} \\
\hline & & Cement & Gravel & Sand & VA & AWA & $\begin{array}{l}\text { Silica } \\
\text { Fume }\end{array}$ \\
\hline \multicolumn{8}{|c|}{ Group 1} \\
\hline SCC-A & 0.40 & 460 & 850.8 & 850.8 & $0.72 \%$ & - & - \\
\hline SCC-C & 0.40 & 414 & 841.5 & 841.5 & $0.97 \%$ & - & 46 \\
\hline SCC -A-AWA & 0.40 & 460 & 844.04 & 844.04 & $1.63 \%$ & $0.15 \%$ & - \\
\hline SCC -C-AWA & 0.40 & 414 & 823.61 & 823.61 & $2.50 \%$ & $0.15 \%$ & 46 \\
\hline \multicolumn{8}{|c|}{ Group 2} \\
\hline SCUWC-C-AWA-0.10 & 0.40 & 414 & 837.61 & 837.61 & 1.45 & $0.10 \%$ & 46 \\
\hline SCUWC-C-AWA-0.15 & 0.40 & 414 & 835.67 & 835.67 & 1.85 & $0.15 \%$ & 46 \\
\hline SCUWC-C-AWA0-.21 & 0.40 & 414 & 833.16 & 833.16 & 2.35 & $0.21 \%$ & 46 \\
\hline SCUWC-C-AWA-0.23 & 0.40 & 414 & 833.72 & 833.72 & $2.30 \%$ & $0.23 \%$ & 46 \\
\hline \multicolumn{8}{|c|}{ Group 3} \\
\hline SCUWC-C-W-0.45 & 0.45 & 414 & 805.93 & 805.93 & $1.80 \%$ & $0.23 \%$ & 46 \\
\hline SCUWC-C-W-0.40 & 0.4 & 414 & 833.72 & 833.72 & $2.30 \%$ & $0.23 \%$ & 46 \\
\hline SCUWC-C-W-0.37 & 0.37 & 414 & 850.06 & 850.06 & $2.60 \%$ & $0.23 \%$ & 46 \\
\hline \multicolumn{8}{|c|}{ Group 4} \\
\hline SCUWC-C-S-60 & 0.40 & 414 & 661.28 & 991.93 & $2.50 \%$ & $0.23 \%$ & 46 \\
\hline SCUWC-C-S-50 & 0.40 & 414 & 833.72 & 833.72 & $2.30 \%$ & $0.23 \%$ & 46 \\
\hline SCUWC-C-S-40 & 0.40 & 414 & 993.93 & 662.62 & $2.20 \%$ & $0.23 \%$ & 46 \\
\hline \multicolumn{8}{|c|}{ Group 5} \\
\hline SCUWC-C-C460 & 0.40 & 414 & 833.72 & 833.72 & $2.30 \%$ & $0.23 \%$ & 46 \\
\hline SCUWC-C-C520 & 0.40 & 468 & 775.43 & 775.43 & $2.20 \%$ & $0.23 \%$ & 52 \\
\hline
\end{tabular}

For the underwater casting, the moulds were oiled first, and then the moulds were positioned in a box filled with water to a depth of $10 \mathrm{~cm}$ above the moulds. A pipe was use as guidance as shown in Fig. 1 . The moulds were slowly retrieved from the water, and their surfaces were struck flat then back to water [4] [8].

The slump flow and $\mathrm{T}_{500}$ time was used to assess the flowability and flow rate of SCUWC as shown in figure 2.The $\mathrm{T}_{500}$ time is also a measure of the speed of flow and, hence the viscosity of the SCC and SCUWC as mentioned in the European guidelines [9]. The L-box test was used to assess the passing ability of SCUWC to flow through tight openings between 
reinforcing bars and other obstructions without segregation or blocking. The sieve segregation resistance test was used to assess the resistance of SCUWC to segregation [9].
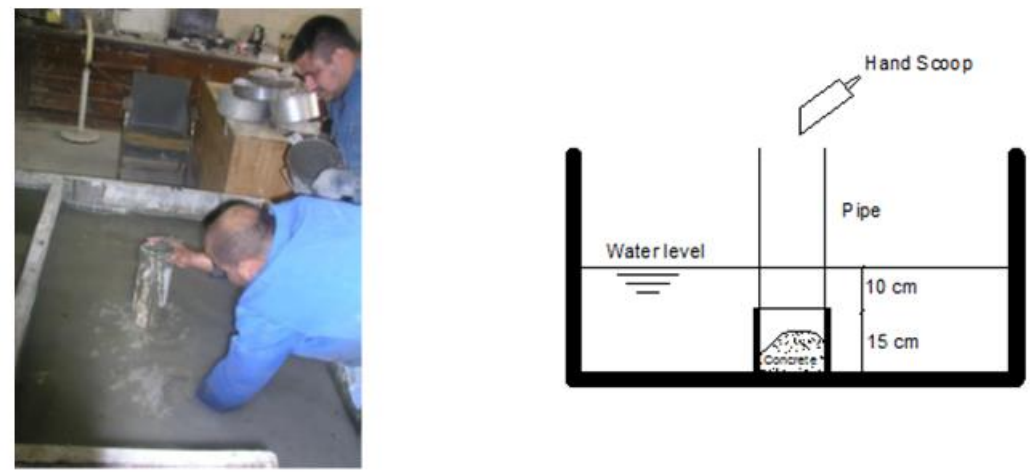

Fig. 1. Underwater casting of concrete samples

\section{Fresh concrete tests}

The washout mass loss was determined in compliance with CRD C61- 89A [10] [11]. The test consists of casting approximately $2 \mathrm{~kg}$ of fresh concrete in a perforated basket and subjecting it to a free fall drop in $1.7 \mathrm{~m}$ of water. Cumulative loss in mass is reported after three drops in water as shown in . After washout tests, the $\mathrm{pH}$ value was recorded as a second indicator for washout as seen in figure 4 where the turbidity of water due to washout results was more alkalinity, this test is recommended by JSCE $[3,12,13]$

\section{Hardened concrete tests}

Compressive strength test was carried out according to the Egyptian Code of Practice. The compressive strength test was made at 28 days. The underwater compressive strength was determined by casting concrete into $150 \times 150 \times 150 \mathrm{~mm}$ cubes filled under water without any consolidation. These results were compared to strengths determined on cubes cast normally.

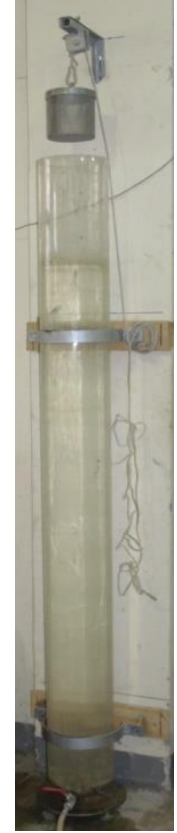

Fig. 3. Washout Apparatus

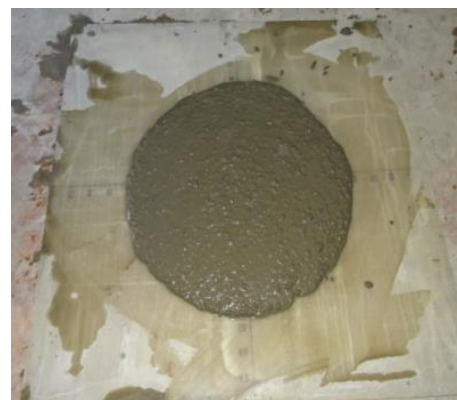

Fig. 2. Slump flow test

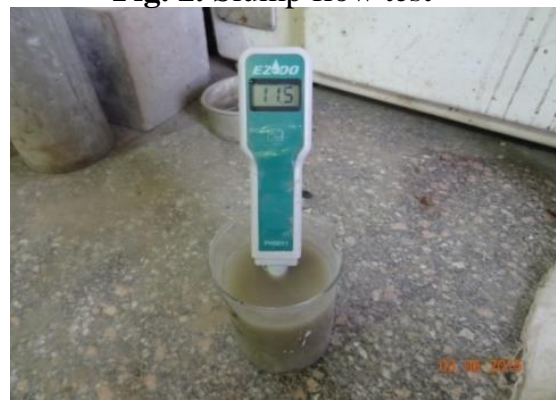

Fig. 4. measuring the $\mathrm{pH}$ value 


\section{Test results and discussion}

The results of all mixture are reported in Table 2.

The strength standard for underwater concrete shall be the test value of a specimen prepared underwater at the age of 28 days, as a rule [3]. The ratio of strength in water to strength in air was calculated at the age of 28 days $(\mathrm{R})$ and listed in Table 2.

Table 2.

Results of mixtures

\begin{tabular}{|c|c|c|c|c|c|c|c|c|c|}
\hline Mix & $\begin{array}{c}\text { D } \\
(\%)\end{array}$ & $\begin{array}{c}\text { SF } \\
(\mathbf{m m})\end{array}$ & $\begin{array}{c}\mathbf{T}_{500} \\
\text { (sec) }\end{array}$ & $\mathbf{P A}$ & $\begin{array}{l}\text { SR } \\
(\%)\end{array}$ & pH & $\begin{array}{c}\mathbf{f c}_{\operatorname{Air}} \\
\left(\mathrm{kg} / \mathrm{cm}^{3}\right)\end{array}$ & $\underset{\left(\mathrm{kg} / \mathrm{cm}^{3}\right)}{\mathrm{fc}_{U W}}$ & $\begin{array}{c}\mathbf{R} \\
(\%)\end{array}$ \\
\hline \multicolumn{10}{|c|}{ Group 1} \\
\hline SCC-A & 17.80 & 600 & 1 & 0.42 & 4.20 & 13.07 & 349.44 & 65.45 & $17 \%$ \\
\hline SCC-C & 12.75 & 620 & 1 & 0.62 & 13.93 & 12.18 & 435.22 & 82.70 & $19 \%$ \\
\hline SCC -A-AWA & 8.60 & 580 & 7 & 0.58 & 6.56 & 11.8 & 367.73 & 199.65 & $54 \%$ \\
\hline SCC -C-AWA & 7.30 & 600 & 3 & 0.72 & 14.81 & 11.56 & 399.85 & 269.28 & $67 \%$ \\
\hline \multicolumn{10}{|c|}{ Group 2} \\
\hline SCUWC-C-AWA-0.10 & 9.50 & 570 & 3 & 0.54 & 11.02 & 11.7 & 431.20 & 239.03 & $55 \%$ \\
\hline SCUWC-C-AWA- 0.15 & 6.64 & 570 & 4 & 0.69 & 9.38 & 11.6 & 415.47 & 249.48 & $60 \%$ \\
\hline SCUWC-C-AWA0-.21 & 5.0 & 560 & 6 & 0.61 & 7.63 & 11.5 & 407.80 & 330.00 & $81 \%$ \\
\hline SCUWC-C-AWA- 0.23 & 4.60 & 550 & 9 & 0.70 & 5.40 & 11.3 & 396.00 & 328.35 & $83 \%$ \\
\hline \multicolumn{10}{|c|}{ Group 3} \\
\hline SCUWC-C-W-0.37 & 3.3 & 550 & 21 & 0.24 & 2.77 & 10.5 & 441.65 & 375.40 & $85 \%$ \\
\hline SCUWC-C-W-0.40 & 4.6 & 550 & 9 & 0.70 & 5.40 & 11.3 & 396.00 & 328.35 & $83 \%$ \\
\hline SCUWC-C-W-0.45 & 5.50 & 600 & 4 & 0.83 & 16.70 & 11.9 & 369.16 & 252.12 & $68 \%$ \\
\hline \multicolumn{10}{|c|}{ Group 4} \\
\hline SCUWC-C-S-40 & 4.91 & 570 & 8 & 0.65 & 9.06 & 11.3 & 400.00 & 328.00 & $82 \%$ \\
\hline SCUWC-C-S-50 & 4.60 & 550 & 9 & 0.70 & 5.40 & 11.3 & 396.00 & 328.35 & $83 \%$ \\
\hline SCUWC-C-S-60 & 3.20 & 550 & 9 & 0.76 & 6.20 & 11.1 & 330.00 & 297.00 & $90 \%$ \\
\hline \multicolumn{10}{|c|}{ Group 5} \\
\hline SCUWC-C-C460 & 4.60 & 550 & 9 & 0.70 & 5.4 & 11.3 & 396.00 & 328.35 & $83 \%$ \\
\hline SCUWC-C-C520 & 4.10 & 570 & 9 & 0.78 & 16.2 & 11.1 & 444.10 & 398.48 & $90 \%$ \\
\hline
\end{tabular}

D: washout mass loss after 3 drops

SF: flowability

$\mathrm{T}_{500}$ : the time recorded for the concrete to reach the $500 \mathrm{~mm}$ circle at any point.

PA: passing ability

SR: segregation resistance

PH: $\mathrm{pH}$ value

Fc Air: Air compressive strength at 28 days

Fc UW: Underwater compressive strength at 28 days

$\mathrm{R}$ : relative compressive strength (underwater strength/air strength) 


\section{Effect of binder composition}

Fig. 3 shows that the effect of supplementary cementitious material and its role in enhancing the washout mass loss and relative strength. Where replacement the cement content with $10 \%$ silica fume leads to reduce the washout mass loss from $17.8 \%$ to $12.75 \%$ in mixtures without AWA and from $8.6 \%$ to $7.3 \%$ in mixtures with AWA, that result in greater relative strengths. The enhancement in this case is due to the replacement of cement content with $10 \%$ silica fume which increases the pozzolanic reaction and viscosity [12].

The $\mathrm{pH}$ results show approximately similar trend as that of the results of washout mass loss, the $\mathrm{pH}$ value decrease in mixes containing silica fume as shown in Fig. 3. This also agrees with the results given in $[13,14]$.

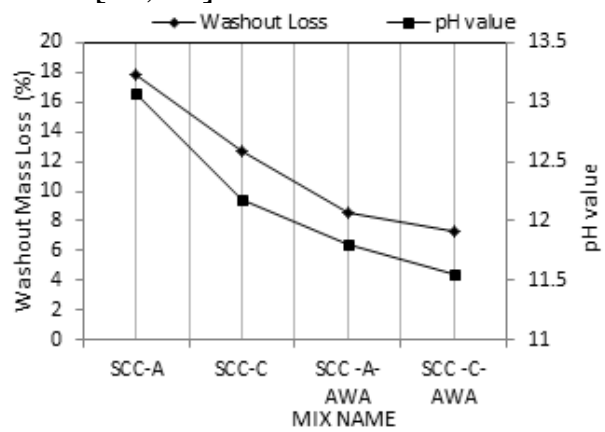

Fig. 3. The effect of binder composition on washout mass loss and $\mathrm{pH}$ value

The effect of binder composition on the variation of relative compressive strength (Underwater strength to air strength) is plotted in Fig. 4. The results show that the mixtures contain silica fume have large relative strength in mixtures with and without AWA.

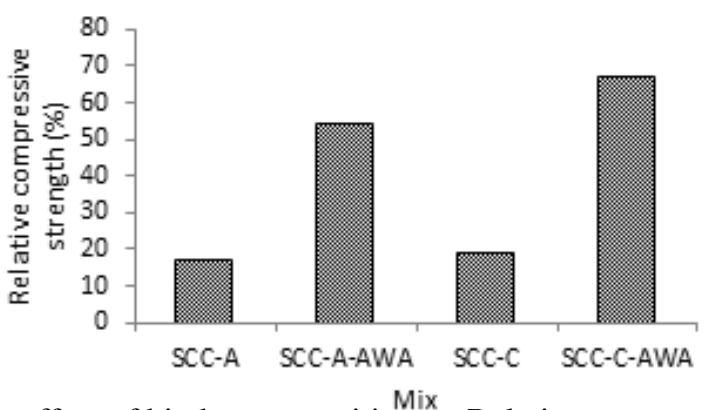

Fig. 4. The effect of binder composition on Relative compressive strength

\section{Effect of AWA content}

The impact of the dosage AWA on the variations of washout mass loss is shown in Fig. 5. For the given consistency, the increase in AWA from $0 \%$ to $0.10 \%$ of cementitious materials resulted in a substantial reduction in washout loss. For example the washout mass loss decreases from $9.5 \%$ at $\mathrm{AWA}=0.10 \%$ to $4.6 \%$ at $\mathrm{AWA}=0.23 \%$.Enhancement in this case is due to the use of AWA which leads to the increase in free water content that reduces the ability of the paste to retain water content and fines, and increases the viscosity of the concrete in the fresh state [13]. 
The figure also shows that the $\mathrm{pH}$ results show approximately similar trend as that of the results of washout mass loss, the $\mathrm{pH}$ value decrease in mixes containing the AWA, the $\mathrm{pH}$ value decreases with increasing the AWA ratio, this corresponds with what came in $[13,14]$.

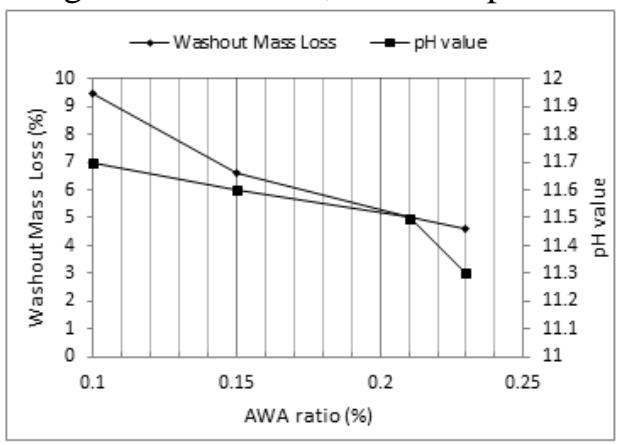

Fig. 5. Effect of AWA on washout mass loss and $\mathrm{pH}$ value

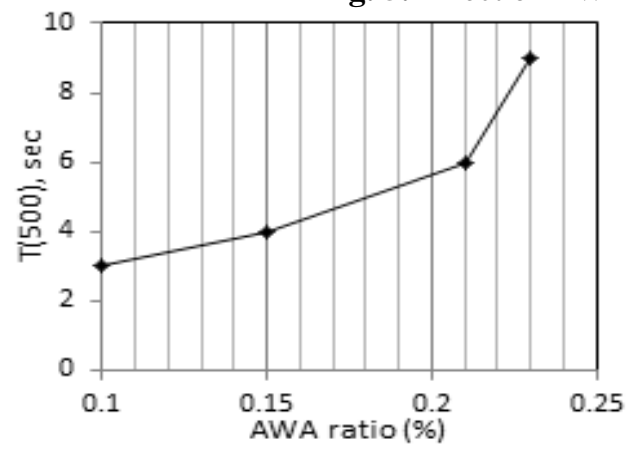

Fig. 6. Effect of AWA ratio on $T_{(500)}$

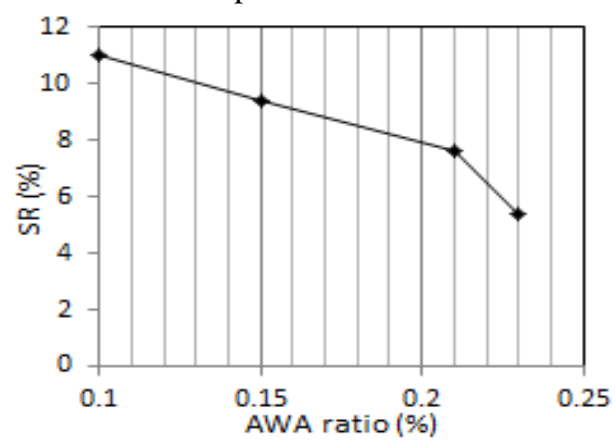

Fig. 7. Effect of AWA ratio on segregation test

Figure 8 shows that increasing the AWA ratio leads to increasing in $T_{500}$ which mean better viscosity as mentioned in the European guidelines, the higher $\mathrm{T}_{500}$ the higher viscosity [9]. Where the $\mathrm{T}_{500}$ increase from $3 \mathrm{sec}$ at AWA ratio $=0.10 \%$ to $9 \mathrm{sec}$ at $\mathrm{AWA}$ ratio $=0.23 \%$.

The results of segregation test in Figure 9 show that increasing the AWA ratio leads to decrease the segregation where segregation ratio $(\mathrm{SR})=11.02$ at $\mathrm{AWA}$ ratio $=0.10 \%$ and $(\mathrm{SR})=5.4$ at $\mathrm{AWA}=0.23 \%$.

The results of passing ability test in Fig. 8 show that increasing the AWA ratio leads to enhance the passing ability behavior. As the AWA led to increase in the viscosity of mixture so the concrete will be more passing ability to flow through tight openings between reinforcing bars and other obstructions without segregation or blocking.

The Fig. 9 shows that the relative compressive strength $(\mathrm{R})$ is shown to increase from $55 \%$ to $83 \%$ with the increase in AWA from $0.10 \%$ to $0.23 \%$. It can be noted that the relative compressive strength increases with weight loss decrease. This also agreed with the results given in [13-16].

For fixed slump flow value, the increase in w/cm from 0.37 to 0.45 resulted in a significant increase in washout mass loss as shown in Fig. 10. For example for slump flow value of $(570 \pm 20) \mathrm{mm}$, the washout mass loss of $0.37 \mathrm{w} / \mathrm{cm}$ is $3.3 \%$ compared to 4.6 and 5.5 in the case of similar mixes with 0.40 and $0.45 \mathrm{w} / \mathrm{cm}$ respectively. This is due to the 
increasing in water content leads to increase the segregation and therefore the water erosion. This also agrees with results given in $[2,4,8]$.

The $\mathrm{pH}$ results show approximately similar trend as that of the results of washout mass loss, the $\mathrm{pH}$ value increases in mixes containing high water content as shown in Fig. 10.

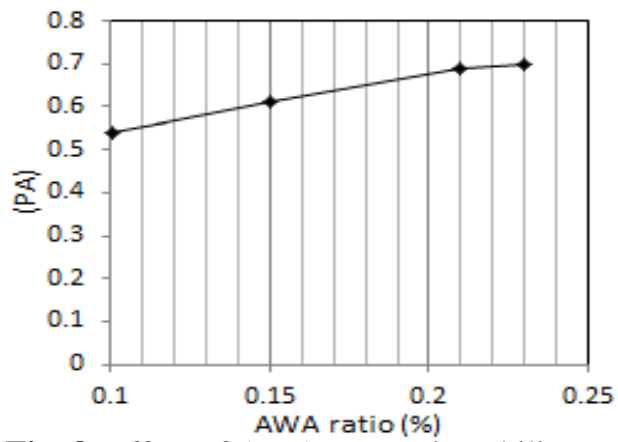

Fig. 8. Effect of AWA on passing ability

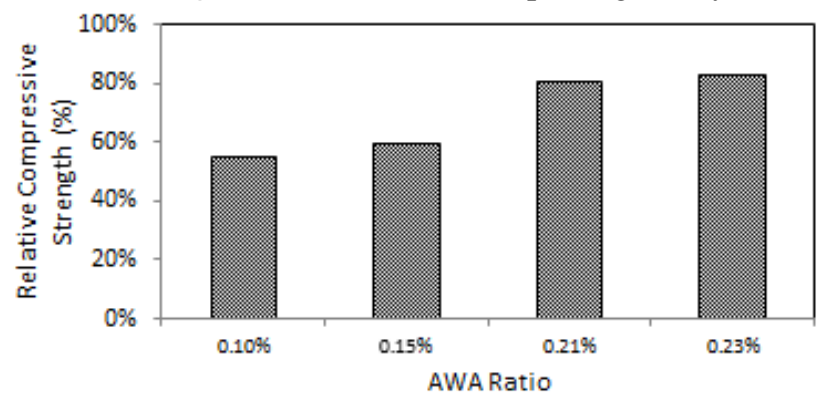

Fig. 9. The effect of AWA ratio on Relative compressive strength

\section{The effect of $\mathrm{W} / \mathrm{CM}$}

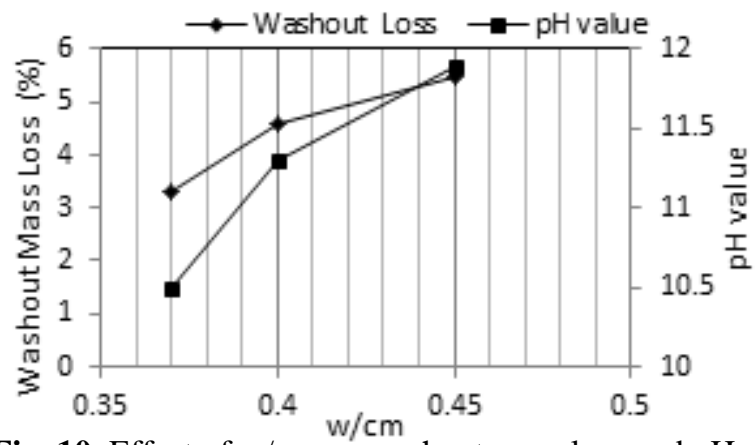

Fig. 10. Effect of $w / \mathrm{cm}$ on washout mass loss and $\mathrm{pH}$ value

Fig. 11 show that the increase in w/cm from 0.37 to 0.45 resulted in a significant decrease in $\mathrm{T}_{(500)}$ which mean lower viscosity. The figure plotted that the $\mathrm{T}_{(500)}$ is $21 \mathrm{sec}$ at $0.37 \mathrm{w} / \mathrm{cm}, 9 \mathrm{sec}$ at $0.40 \mathrm{w} / \mathrm{cm}$ and $4 \mathrm{sec}$ at $0.45 \mathrm{w} / \mathrm{cm}$.

The results of segregation test in figure 14 show that increasing the $\mathrm{w} / \mathrm{cm}$ ratio resulted in a significant increase in segregation where segregation ratio $(\mathrm{SR})=2.77$ at $\mathrm{w} / \mathrm{cm}=0.37$ and $(\mathrm{SR})=16.7$ at $\mathrm{w} / \mathrm{cm}=0.45$.

The results of passing ability test in Fig. 13 show that increasing the w/cm ratio leads to enhance the passing ability behavior. 
For a given washout loss, the increase in $w / \mathrm{cm}$ is shown to reduce the relative compressive strength as shown in Fig. 14.

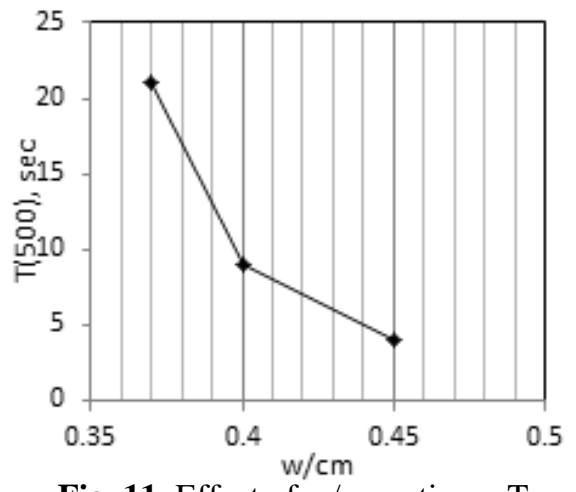

Fig. 11. Effect of $w / \mathrm{cm}$ ratio on $T_{(500}$

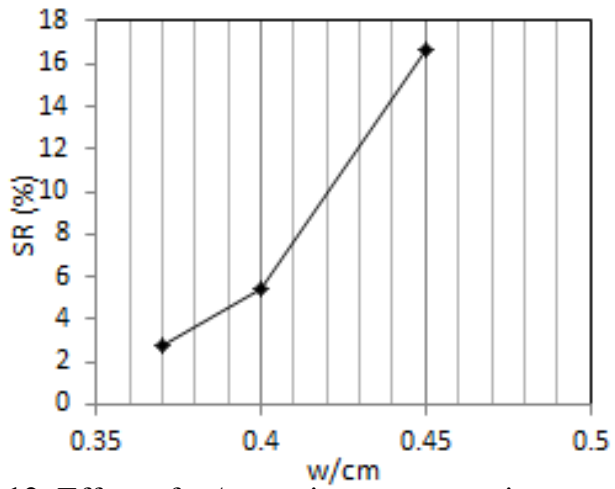

Fig. 12. Effect of w/cm ratio on segregation test

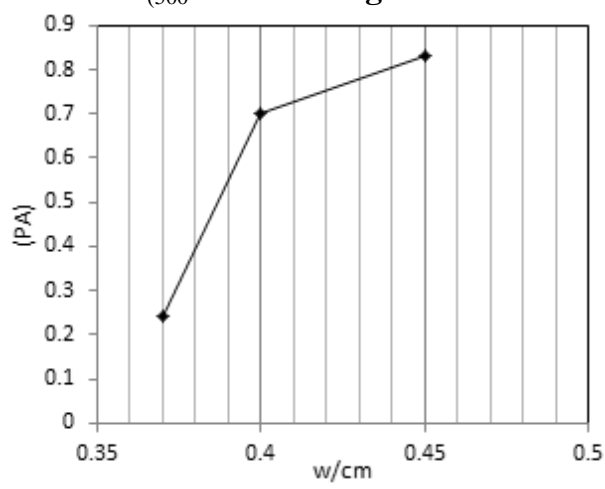

Fig. 13. Effect of $w / \mathrm{cm}$ ratio on passing ability.

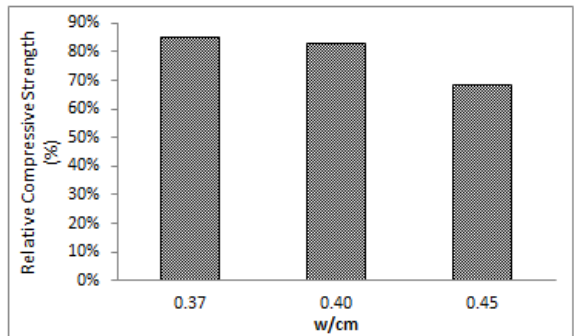

Fig. 14. The effect of $w / \mathrm{cm}$ ratio on Relative compressive strength

\section{Effect of S/A ratio}

For a given slump flow value $(570 \pm 20) \mathrm{mm}$, the increase in (s/a) from $40 \%$ to $60 \%$ resulted in a decrease in washout mass loss as shown in Fig. 15. It can be noticed from the figure, the washout mass loss of the mixtures (SCUWC-C-S-40\%) and (SCUWC-C-S$50 \%$ ) are rather similar. While, washout mass loss of (SCUWC-C-S-60\%) mixture showed lower values than the other two mixtures. The $\mathrm{pH}$ results show approximately similar trend as that of the results of washout mass loss, as shown in Fig. 15.

Fig. 16 shows that the $\mathrm{T}_{500}$ of all mixtures are rather similar. 
The results of segregation test in Fig. 17 shows that increasing the s/a ratio from (40\% to $60 \%$ ) resulted in decreasing the segregation.

The results of passing ability test in Fig. 18 show that increasing the s/a ratio leads to enhance the passing ability behavior.

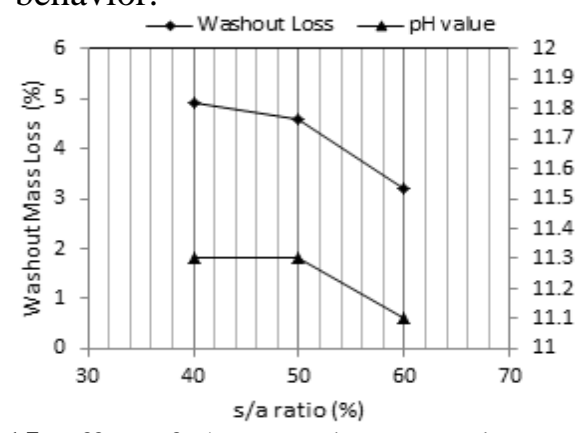

Fig. 15. Effect of s/a on washout mass loss and $\mathrm{pH}$ value.

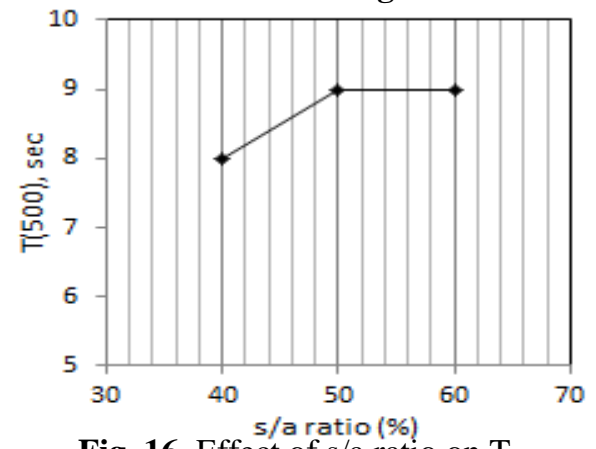

Fig. 16. Effect of s/a ratio on $T_{(500)}$

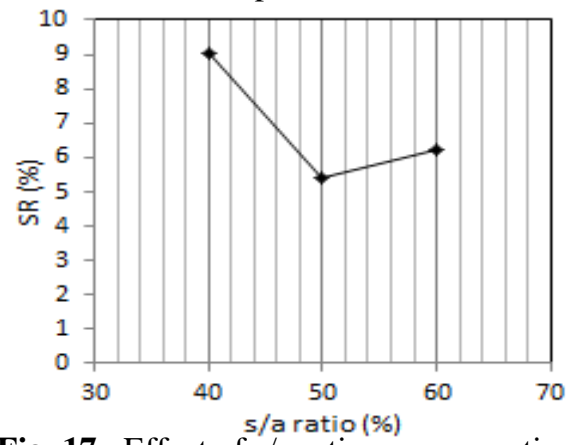

Fig. 17. Effect of s/a ratio on segregation test

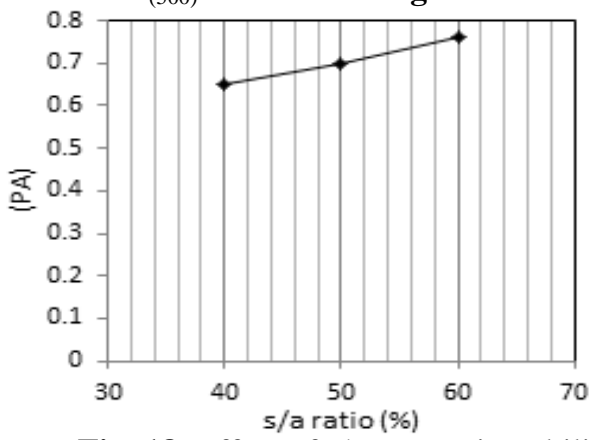

Fig. 18. Effect of s/a on passing ability.

Fig. 19 shows that the relative compressive strength $(\mathrm{R})$ is shown to increase from $82 \%$ to $90 \%$ with the increase in s/a ratio from $40 \%$ to $60 \%$. Where the relative compressive strength (R) is $82 \%$ at the s/a is $40 \%$ and (R) is $90 \%$ at the s/a is $60 \%$

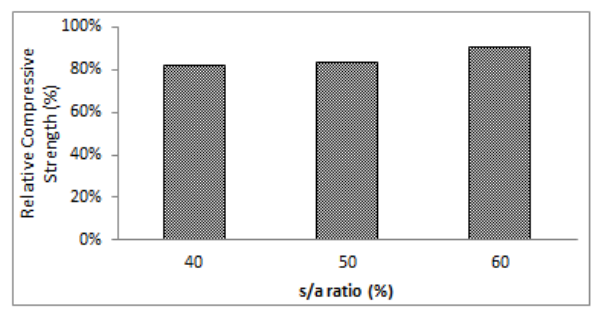

Fig. 19. The effect of w/cm ratio on Relative compressive strength 


\section{Effect of cementitious materials (CM)}

For a given slump flow value $(570 \pm 20) \mathrm{mm}$, the increase in $(\mathrm{CM})$ from $460 \mathrm{~kg} / \mathrm{m}^{3}$ to 520 $\mathrm{kg} / \mathrm{m}^{3}$ resulted in a decrease in washout mass loss as shown in Fig. 20. The washout mass loss decreases from $4.6 \%$ at $\mathrm{CM}=460 \mathrm{~kg} / \mathrm{m}^{3}$ to $4.1 \%$ at $\mathrm{CM}=520 \mathrm{~kg} / \mathrm{m}^{3}$. This may be due to the relative increase of cement paste volume when the cement content was increased in the mix [13].

The $\mathrm{pH}$ results show approximately similar trend as that of the results of washout mass loss, the $\mathrm{pH}$ value decrease in mixes contain high content of cement as shown in Fig. 20, this is attributed to increasing the cement content will increase the cohesion of the mixture and this leads to decrease the washout mass loss and subsequently decrease the $\mathrm{pH}$ value of the water. This also agrees with the results given in $[3,13]$

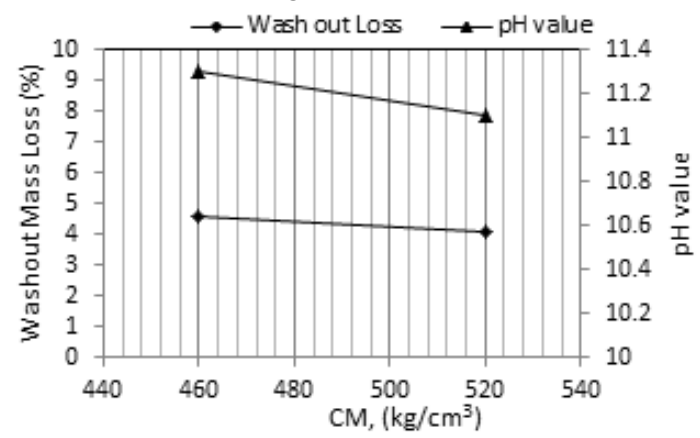

Fig. 20. Effect of $\mathrm{CM}$ on washout mass loss and $\mathrm{pH}$ value.

Fig. 21 shows that the $\mathrm{T}_{500}$ of all mixtures are rather similar.

The results of segregation test in Fig. 22 shows that increasing the CM from (460 to $520) \mathrm{kg} / \mathrm{m}^{3}$ leads to increase the segregation. This is due to the high water content and use high dose of VA to adjust the required slump flow.

The results of passing ability test in

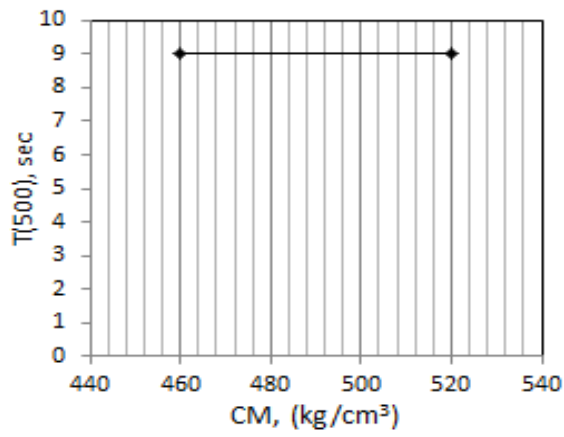

Fig. 21. Effect of CM ratio on $\mathrm{T}_{(500)}$

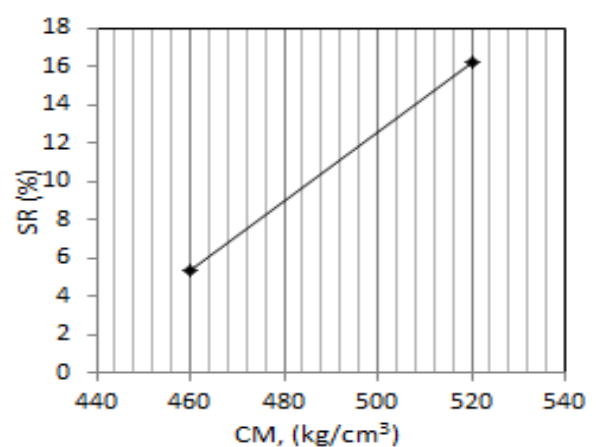

Fig. 22. Effect of $\mathrm{CM}$ ratio on segregation test

Fig. 24 shows that the relative compressive strength (R) is shown to increase from $83 \%$ to $90 \%$ with the increase in CM from $460 \mathrm{~kg} / \mathrm{m}^{3}$ to $520 \mathrm{~kg} / \mathrm{m}^{3}$. 


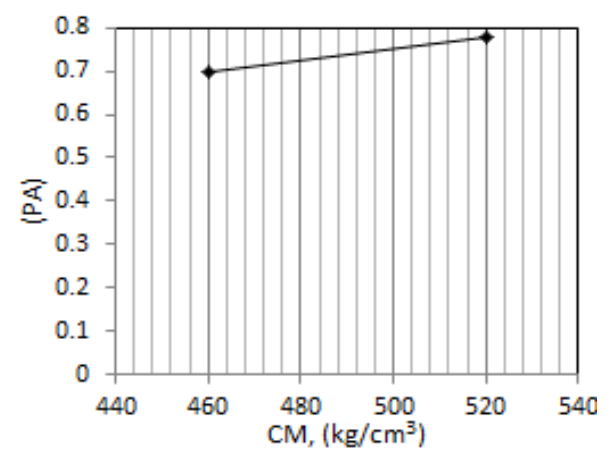

Fig. 23. Effect of (CM) on passing ability.

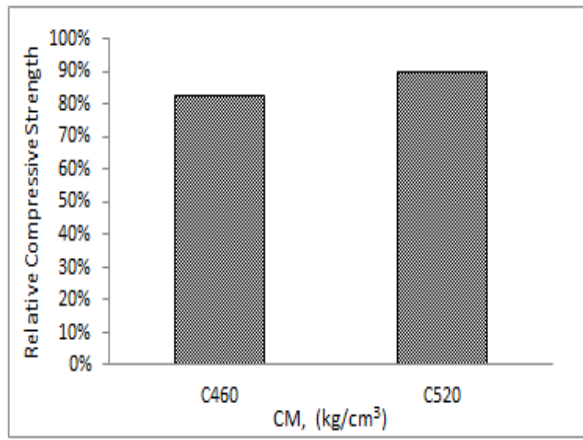

Fig. 24. The effect of (CM) ratio on Relative compressive strength

\section{Conclusion}

Based on the previous test results the following points appear to be concluded:

1. The Replacement of cement content with $10 \%$ silica fume led to enhance the washout resistance and relative strength by $15 \%$ and $24 \%$ respectively.

2. Adding the AWA led to significant decrease in washout mass loss that result in greater relative strength, depend on the (VA) where the result of increasing the AWA is increasing the demand of (VA).

3. The increasing in AWA ratio from $0.10 \%$ to $0.23 \%$ for concrete made with 0.40 w/cm and $460 \mathrm{~kg} / \mathrm{m}^{3} \mathrm{CM}$ resulted in $51 \%$ lower washout and $51 \%$ higher relative strength at slump flow $(570 \pm 20) \mathrm{mm}$.

4. The $\mathrm{pH}$ value decreased with the reduction of the washout mass loss.

5. The reduction of $w / \mathrm{cm}$ from 0.45 to 0.37 for concrete made with $0.23 \%$ AWA resulted in $40 \%$ lower washout and $25 \%$ higher relative strength at slump flow $(570 \pm 20) \mathrm{mm}$.

6. The increasing in s/a ratio from $40 \%$ to $60 \%$ for concrete made with $0.23 \%$ AWA resulted in 35\% lower washout and 9\% higher relative strength at slump flow $(570 \pm 20) \mathrm{mm}$.

7. The increasing in $\mathrm{CM}$ from $460 \mathrm{~kg} / \mathrm{m}^{3}$ to $520 \mathrm{~kg} / \mathrm{m}^{3}$ for concrete made with $0.23 \%$ AWA resulted in $11 \%$ lower washout and $8 \%$ higher relative strength at slump flow $(570 \pm 20) \mathrm{mm}$.

8. Increasing the AWA ratio led to decrease the segregation.

9. Decreasing the $w / \mathrm{cm}$ led to decrease the segregation.

10. For the same w/cm ratio improving the washout resistance was accompanied by slightly enhancing the passing ability property. 


\section{REFERENCES}

[1] H. S. Najm, Concrete Construction Engineering Handbook, New Jersey: Taylor \& Francis Group, LLC, 2008.

[2] K. Khayat, A. Yahia and M. Sonebi, “Applications of Statistical Models for Proportioning Underwater Concrete,” ACI Materials Journal, vol. 96, no. 6, pp. 634-641, 1999.

[3] "RECOMMENDATIONS FOR DESIGN AND CONSTRUCTION OF ANTIWASHOUT UNDERWATER CONCRETE," Japan Society of Civil Engineers (JSCE), JAPAN, 1991.

[4] K. H. Khayat and J. Assaad, "Relationship between Washout Resistance and Rheological Properties of High-Performance Underwater Concrete," ACI MATERIALS JOURNAL, vol. 100, no. 3, pp. 185-193, 2003.

[5] M. Sonebi and K. khayat, "Effect of Free-Fall Height in Water on Performance of Highly Flowable Concrete," ACI Materials Journal, 2001.

[6] The Egyption Standard Specification, "ES 4756-1 (2009) Cement Part:(1) Composition, Specifications And Conformity Criteria For Common Cements," Egyptian Organization for Standardization and Quality (EOS), Egypt, 2009.

[7] Sika Egypt for construction chemicals, Egypt, [Online]. Available: http://www.sika.com.eg..

[8] k. Khayat and M. Sonebi, "Effect of Mixture Composition on Relative Strength of Highly Flowable Underwater Concrete," Aci Materials Journal, vol. 98, no. 3, pp. 233-239, 2001.

[9] "The European Guidelines for Self-Compacting Concrete Specification, Production and Use," May 2005. [Online]. Available: www.efca.info or www.efnarc.org.

[10] CRD C61-89A," Test Method For Determining The Resistance Of Freshly-Mixed Concrete To Washing Out In Water", U.S.Army Experiment station,Vicksburg,Miss, 1989.

[11] D. E. B. B. C. G. Sam X. Yao, "Assessment of Underwater Concrete Technologies for In-theWet Construction of Navigation Structures," US Army Corps of Engineers,Engineer Research and Development Center, San Francisco, September 1999.

[12] M. Benaicha, X. Roguiez, O. Jalbaud, Y. Burtschell and A. H. Alaoui, "Influence of silica fume and viscosity modifying agent on the mechanical and rheological behavior of self compacting concrete," Construction and Building Materials, vol. 84, pp. 103-110, 2015.

[13] A. M. H. Alsaeed Abd El Salam Maaty and Ibrahim Saad Agwa, Simulation of the behavior of pressurized underwater concrete, Alexandria: Alexandria Engineering Journal (2015) 54, 183 195, April 2015.

[14] A. M. Heniegal, "Behaviour Of Underwater Self Compacting Concrete," Journal of Engineering Sciences,Assiut University, vol. 40, no. 4, pp. 1005-1023, July 2012.

[15] M. Imam, "The use of anti-washout admixtures in underwater," in Egyptian Engineers Association of the 2nd Conference, Riyad, 15-17 May, 2010..

[16] E. Ali and E. Kattab, "Self-flowing under-water concrete mixtures with and without antiwashout admixture J. Eng.,” J. Eng.Res. Azhar University Egypt., 2013. 


\section{تأثير نسب الخلط على مقاومة الغسيل والخواص الطازجة والمقاومة النسبية للخرسانة ذاتية الدمك المصبوبة تحت المباء}

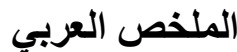

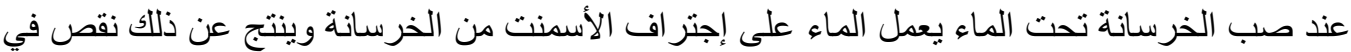

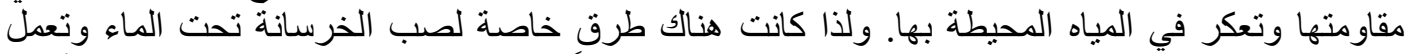

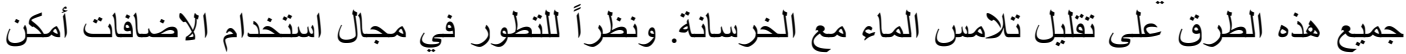

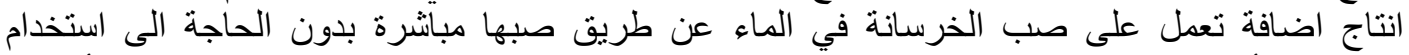
(tremie)

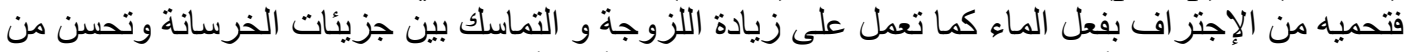
مقاومتها للانفصال. و لأنتاج هذا النوع من الخرسانة يتطلب الأمر بأن تكون الخرسانة متماسكة و ذانية الدمك

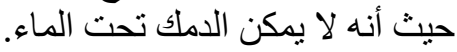

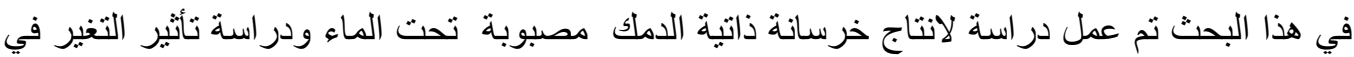

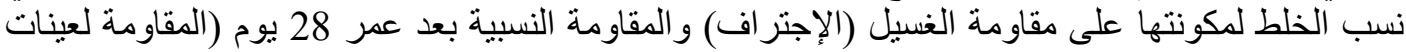

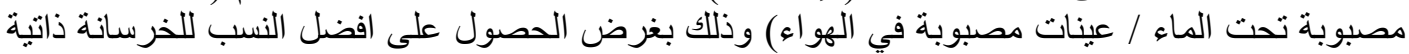
الدمك لتحقيق المنطلبات القياسية للأختبا ا رت الخاصة بالصب تحت الماء.

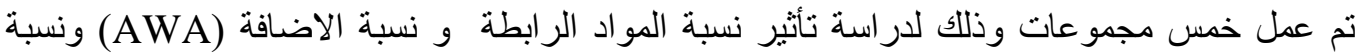

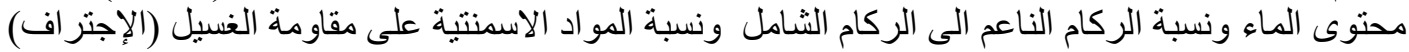

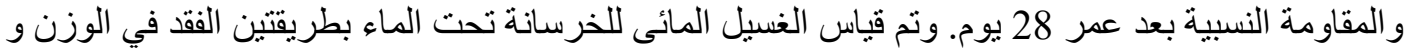

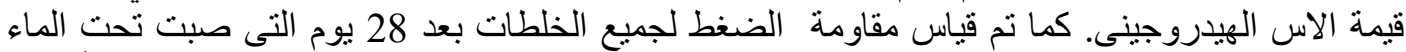

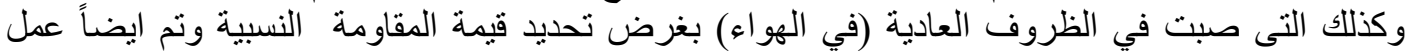
اختبار هبوط الانسياب واختبار مقاومة الانفصسال الحيبي واختبار(L-box) .

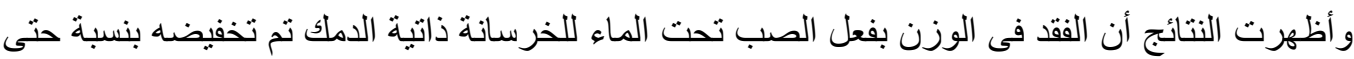

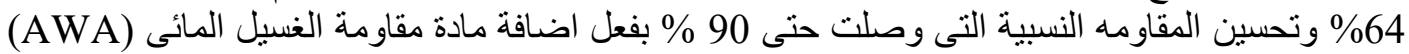

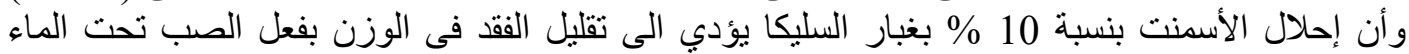

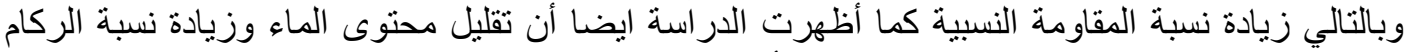

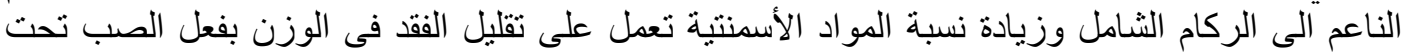

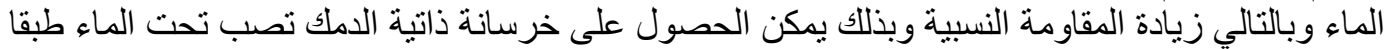

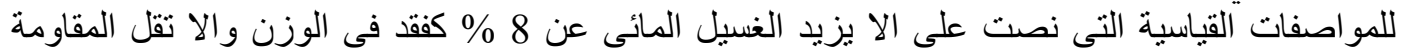
النسبية عن 80 \% كما نصت المو اصفات الامريكية و اليابانية . 